\title{
The Importance of Place in Communicating Climate Change to Different Facets of the American Public ?
}

\author{
AbBy Halperin AND Peter Walton \\ University of Oxford, Oxford, United Kingdom
}

(Manuscript received 25 October 2016, in final form 7 June 2017)

\begin{abstract}
While the need for action on climate change is urgent, individual-level behaviors to mitigate or adapt to the problem have not tracked with the increasing urgency for action. Place-based communication of climate change may catalyze action by making climate change more personally relevant. However, there is no one general public, so communication efforts can unintentionally polarize beliefs. This study aims to fill the gap in knowledge about how and why different audiences respond to place-based climate change communication, which could aid climate change communication efforts and climate scientists. Results from an experimental survey of 655 Californians and follow-up interviews indicate that prior climate change beliefs influence the effectiveness of place-based climate change communication. In particular, those who were already "concerned" about climate change, as classified by the Six Americas, were the only group to show a significant response to an intervention. This study also finds no difference in willingness to adapt to climate change between local and global framings. However, those exposed to a local framing were more likely to take personal-scale adaptation actions, while those exposed to a global framing were more likely to take policyscale adaptation actions. These results, and the theories of place attachment and psychological distance, suggest that place-based communication may only be applicable for certain audiences (e.g., the concerned) and when the scale of the intervention matches the scale of action.
\end{abstract}

\section{Introduction}

The question of what motivates people to take action on climate change is increasingly important with the abundant evidence that mitigation and adaptation are needed (IPCC 2014). However, not enough is being done to meet the Paris Agreement's goals (UNFCCC 2015) with countries' current pledges (Climate Action Tracker 2015). Even if these mitigation targets are met, the public needs to be prepared for some warming (Evans et al. 2014). Public support is critical in meeting these goals, both through policy support and individual behavior change (Willis and Eyre 2011).

Research suggests one reason individual behaviors have been insufficient to mitigate and adapt to climate change, particularly in countries like the United States

Supplemental information related to this paper is available at the Journals Online website: https://doi.org/10.1175/WCASD-16-0119.s1.

Corresponding author: Abby Halperin, abbyhalperin@gmail. com
(Leiserowitz 2007; Lorenzoni and Hulme 2009; O’Neill and Nicholson-Cole 2009), is that climate change is perceived as distant in time and space (e.g., Beard and Thompson 2012; Hulme 2009). Images used in climate change communication such as polar bears and icebergs (Hulme 2009; Nerlich and Jaspal 2014) combined with rhetoric about saving the planet for our children (e.g., Dunaway 2015) exacerbate the perception that climate change is a distant phenomenon. Communication efforts may prompt action by framing climate change more locally (e.g., Scannell and Gifford 2013), though there are conflicting results about when local framing is effective (Brügger et al. 2015a; Spence et al. 2012).

A new way to communicate local impacts of climate change is through probabilistic event attribution (Allen 2003; Stott et al. 2004), which quantifies whether and how much anthropogenic climate change shifts the likelihood of extreme weather events such as floods (Pall et al. 2011), droughts (Funk et al. 2014; Swain et al. 2014), and heat waves (Otto et al. 2012). Through extreme event attribution, the impacts of climate change on specific places can be described soon after they have happened, making climate change more tangible to 
stakeholders, such as those from nonprofits, government agencies, and businesses (Sippel et al. 2015). The attribution of extreme weather events has already sparked interest among the public, as the media increasingly ask who is to blame for devastating weather events (Hulme 2014; Stott and Walton 2013). This new area of scientific research offers an unprecedented opportunity for situating the impacts of climate change in the here and now.

Responses to the attribution of extreme weather events can be examined using the theory of place attachment. Place attachment, the emotional connections between people and places (Lewicka 2011; Scannell and Gifford 2010), can be leveraged for action when personally important locations are threatened (Scannell and Gifford 2013). Scannell and Gifford (2010) developed a tripartite framework for understanding how person, place, and process intersect in creating attachment to place, with attachment to the physical characteristics of a place typically leading to more proenvironmental behaviors. As place attachment can be formed at multiple nested scales (Hess et al. 2008; Laczko 2005), the effectiveness of locally or globally framed communication may be influenced by local or global place attachment.

Place-based communication of climate change can also be explored through the theory of psychological distance. Psychological distance is defined in reference to the self and measures how far away a concept is located in temporal, spatial, hypothetical, and social distance (Trope and Liberman 2010). Climate change is often perceived to be far away in all four of these dimensions, as it might happen in the future, in other places, to other people (Lorenzoni and Hulme 2009). This theory suggests that if climate change becomes closer psychologically, then people will become more personally concerned and therefore more willing to act (Spence et al. 2012).

Construal-level theory, which is related to but distinct from psychological distance, states that concepts located far away on the dimensions of psychological distance will be conceptualized more abstractly (Trope and Liberman 2010). The level of construal is a measure of abstractness (Trope and Liberman 2010), such that the climate would have a higher level of construal than a thunderstorm, which is a specific manifestation of weather. Since a higher level of abstractness leads to behaviors that are more in line with core values, construal-level theory would predict that greater psychological distance leads to more action on climate change mitigation, which is considered to be a relatively abstract and global effort (Spence et al. 2012; Haden et al. 2012). Therefore, construal-level theory indicates that people may be more willing to act on abstract things that are located far away on these four dimensions of distance (Spence et al. 2012; Trope and Liberman 2010).
Reconciling these two opposing theories about whether decreasing psychological distance leads to action, Brügger et al. (2015a) propose that the psychological proximity of climate change can be effective, backfire, or produce no result, depending on the other conditions surrounding the communication. Namely, making climate change more proximate will only be effective if people have an attachment to the place and if they judge themselves to be capable of taking action (Brügger et al. 2015a). They also suggest that the level of construal should match the scale of action (Brügger et al. 2015a; Trope and Liberman 2010), with concerns about proximate climate conditions leading to personal adaptation efforts and global concerns leading to mitigation efforts (Haden et al. 2012).

Place attachment and psychological distance suggest, but not unequivocally, that locally based communication will be more effective at increasing the public's willingness to mitigate and adapt to climate change. However, these responses may not persist across all audiences, as people's prior beliefs and values have a strong bearing on how they respond to communication efforts (e.g., Leiserowitz 2007; Lorenzoni and Hulme 2009; Schweizer et al. 2013).

To fill the gap in knowledge about how different audiences respond to place-based climate change communication, this study examines the following research questions:

1) Is locally or globally framed communication more effective in increasing willingness to mitigate and/or adapt to climate change?

2) How do people with different beliefs and values about climate change respond to place-based communication?

3) Can the theories of place attachment and/or psychological distance help explain why people respond to place-based communication?

These research questions guide this work on whether people change their behaviors in response to locally framed climate change communication, who responds to this type of communication, and why they respond as they do.

\section{Method}

A mixed methods approach was used to understand whether, for whom, and why place-based communication of climate change might be effective at changing behaviors. A survey of Californians $(n=655)$ in the summer of 2015 compared the changes in willingness to adapt and mitigate climate change among those exposed to either a locally or globally framed intervention or a 


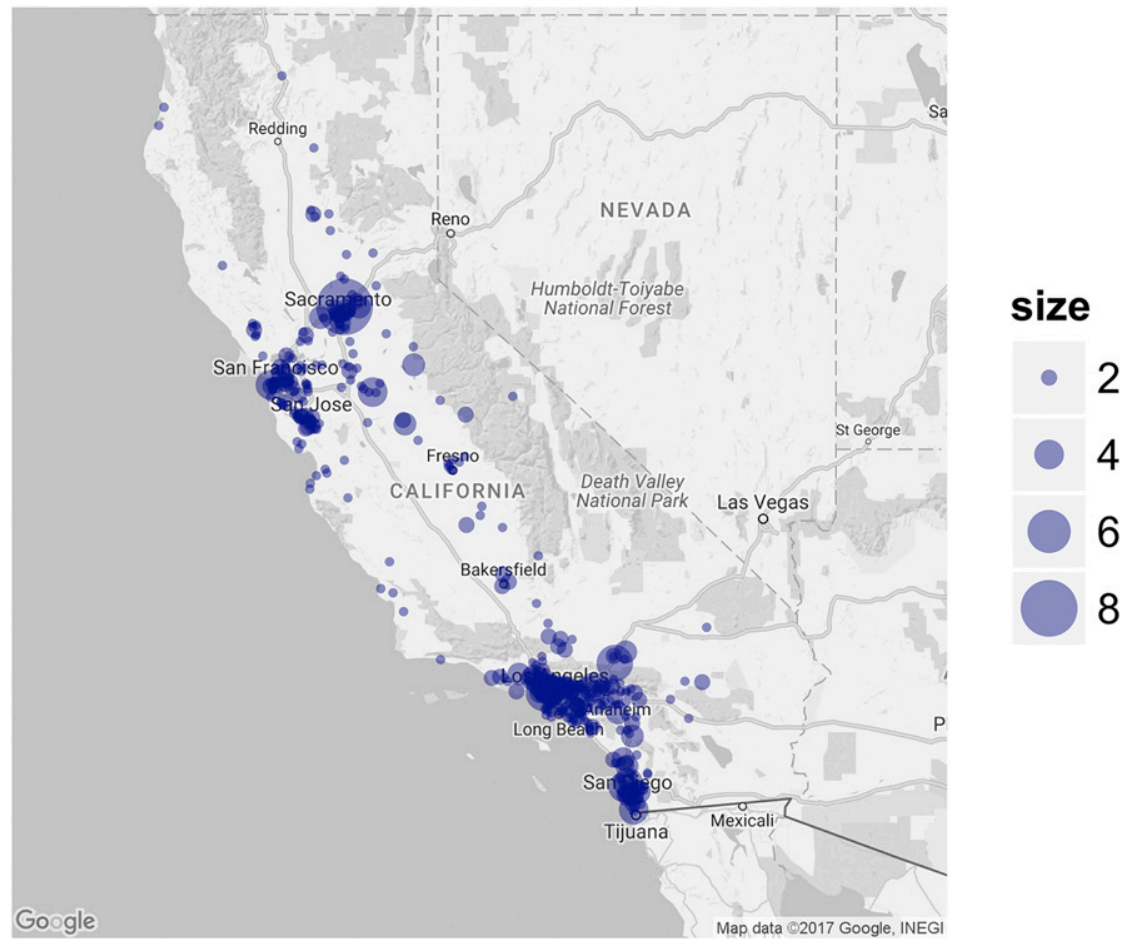

FIG. 1. The distribution of survey participants within the state of California. Blue circles are sized proportionately with the number of participants in each zip code. (Base map provided by Google Maps).

control condition. Follow-up interviews complemented the survey by providing a more nuanced understanding of responses (Creswell and Plano Clark 2011).

\section{a. California case study}

California experienced the fourth winter of severe and widespread drought in 2014/15 (Nagourney 2015; National Drought Mitigation Center 2015) exacerbated by high temperatures caused by anthropogenic climate change (AghaKouchak et al. 2014; Williams et al. 2015). Given the influence of climate change on the likelihood of the drought, California residents were an ideal population to test whether making this attribution statement would influence their behaviors. The scale of the state is appropriate in this context as, unlike in other countries, Americans generally have a greater attachment to their state than to their neighborhood or city (Laczko 2005), though most place attachment research has focused on smaller scales (Lewicka 2011). However, beliefs about climate change in California do differ from other states (Howe et al. 2015).

\section{b. Sampling strategy}

The sample population spans California, with more respondents from large cities (Fig. 1). California residents were recruited through an Internet-based sampling tool, Amazon's Mechanical Turk platform. Mechanical Turk pays users a nominal fee (in this case, $\$ 0.50-\$ 1.00$ ) to complete a task and has produced results similar to other sampling strategies (Simons and Chabris 2012; Sprouse 2011). Participation was restricted to Mechanical Turk workers who had at least a $98 \%$ approval rate on more than 500 tasks to ensure data quality (Peer et al. 2014; Paolacci and Chandler 2014). One limitation is that while $86 \%$ of Americans use the Internet, this dwindles to $59 \%$ among those older than 65 (Smith 2014).

\section{c. Survey design}

To examine the importance of place in climate change communication, the survey follows an experimental approach similar to the methods employed by Scannell and Gifford (2013) and Hart and Nisbet (2011). The survey consisted of closed-ended response questions delivered through an online survey tool (Survey Monkey), with more nuanced responses obtained through follow-up interviews (see supplemental material at the Journals Online website: https://doi.org/10.1175/ WCAS-D-16-0119.s1 for survey and interview questions).

After consenting, survey participants were assigned randomly using Survey Monkey's A/B testing function to one of three conditions: 
1) Local: a text about the role of climate change in the California drought

2) Global: a text about climate change and worldwide droughts

3) Control: no text

In the local and global interventions, the text and image were identical with the exception of words or phrases that referred to places. The local and global messages were both a page of text in the style of a newspaper article, with a picture of a dry riverbed (see supplemental material at the Journals Online website: https://doi.org/10.1175/ WCAS-D-16-0119.s1). The attribution statement in the local intervention read: "The higher temperatures that strengthen the drought in California are more likely to occur in a world with human-caused climate change." For the global intervention, the phrase "drought in California" was replaced with "droughts worldwide."

Measures of willingness to adapt (11 questions) and mitigate climate change (5 questions) were used to test the effectiveness of climate change communication (G. Gottlieb 2015, personal communication). Questions were in the form of statements such as "I intend to prepare for the impacts of climate change in my daily life" with seven Likert-scale responses ranging from strongly disagree to strongly agree (Blasius and Thiessen 2012).

Questions about place attachment, which may mediate the response to place-based communication, focused on location, residence time (Lewicka 2011), the tendency to stay (Billig 2006), and community size (Lewicka 2011). Following Laczko (2005), five questions were asked about attachment to places at different scales (ranging from the neighborhood to North America). An additional question reflected Devine-Wright's (2013) theory that attachment could also be formed to the planet. After Jorgensen and Stedman (2006), 12 questions were asked about participant's cognitive, emotional, and behavioral connections to California. Finally, a few questions targeted the connection to physical characteristics and/or the people in the state, reflecting the tripartite framework (Scannell and Gifford 2010).

To understand psychological distance in climate change communication, seven questions were asked about temporal, spatial, social, and hypothetical distance to climate change (G. Gottlieb 2015, personal communication) that were similar to those employed by Spence et al. (2012). For example, one question asked, "Where will the impacts of climate change be felt?" with answers ranging from "right here" to "distant countries." Additional answer options of "nowhere" and "everywhere" were provided to include the possibility of dismissing climate change in the first case and concern about global impacts in the latter.
To examine how people's beliefs and ideologies influence their response to climate change communication, the Six Americas framework (Maibach et al. 2011) was used to divide participants into six groups: alarmed, concerned, cautious, disengaged, doubtful, and dismissive. The 15 questions and procedure used to construct the Six Americas are identical to those described by Maibach et al. (2011) and include the participants' beliefs about the certainty of climate change, the causes of global warming, and the degree to which they expect it will affect them personally.

Demographic information such as age, income, and education was used to assess the representativeness of the sample through comparison with U.S. Census data (U.S. Census Bureau 2000, 2010). The survey followed the University of Oxford's Central University Research Ethics Committee (CUREC; University of Oxford 2016) procedures to ensure participants' dignity and safety.

\section{d. Survey execution and analysis}

To avoid introducing a selection response, climate change was not mentioned in the description or promotion of the survey. Though 655 people began the survey, only the 609 complete survey responses were used. Surveys with identical IP addresses and responses or with response times greater than 30 minutes or less than 4 minutes were removed (G. Gottlieb 2015, personal communication) to improve data quality (Krupa et al. 2014; Kittur et al. 2008), leaving 589 cases for analysis. Likert-scales responses were translated into a numeric scale.

Many of the variables used in the subsequent analysis are composed of multiple items, as composite variables provide a wider variance between respondents and allow for occasional misunderstandings of individual questions (Blasius and Thiessen 2012; Bryman and Cramer 2011). The following composite variables were tested for internal reliability using Cronbach's alpha, where $\alpha>0.70$ indicates sufficient reliability (Nunnally 1978):

1) Willingness to adapt: average of the 5 adaptation questions $(\alpha=0.83)$

2) Willingness to mitigate: average of the 11 mitigation questions $(\alpha=0.85)$

3) Place attachment: average of the 12 questions relating to the cognitive, emotional, and behavioral connections to California $(\alpha=0.92)$

4) Psychological distance: average of the 7 psychological distance questions $(\alpha=0.94)$

A Kolmogorov-Smirnov test, used to check the normality of these composite variables, found that all four 
variables were nonnormal ( $p<0.001)$. Because of nonnormality, even with typical transformations of the data, nonparametric tests were used. When linear regressions were attempted, the residuals exhibited heteroscedasticity (Wilcox 2004), so a nonparametric Spearman's correlation was used instead, which does not assume homogeneity of variance for the residuals (Coleman 2010).

The effects of test condition on willingness to mitigate and adapt to climate change were examined for the entire sample and within the Six Americas groups using a Kruskal-Wallis $\mathrm{H}$ test. Post hoc tests were conducted to establish pairwise comparisons between significantly different groups using the Bonferroni correction to adjust $p$ values. For place attachment and psychological distance, the correlations with willingness to adapt for the test conditions and within the Six Americas were examined using Spearman's correlation.

\section{e. Interview execution and analysis}

Follow-up interviews were conducted to allow for themes to emerge outside of the structured survey format. Interviewees were selected from the 248 survey participants $(41 \%$ of the sample population) who indicated their willingness to be interviewed for a payment of \$7.00. A stratified random sample approach was used to select two participants from each of the Six Americas who had ideally been exposed to different (local or global) test conditions.

The 12 interviews were conducted using a semistructured approach to allow the opportunity to follow up on interesting ideas or probe for more explanation while using a standardized set of questions (see supplemental materials at the Journals Online website: https:// doi.org/10.1175/WCAS-D-16-0119.s1) and order for each participant (Clifford et al. 2010). Oral consent was obtained at the beginning of each phone or Skype interview following CUREC procedures (University of Oxford 2016). The average interview lasted $22 \mathrm{~min} 21 \mathrm{~s}$ $(\mathrm{SD}=8 \mathrm{~min} 24 \mathrm{~s})$. All interviews were fully transcribed.

The interviews were analyzed using the major research questions and emerging themes (Holliday 2007). The importance of place-based communication of climate change was examined through responses to questions about how the California drought compares to both global patterns in extreme weather events and extreme events elsewhere in the world. Place attachment was analyzed by collating responses from questions about living in California and organizing these responses into subthemes based on the tripartite framework proposed by Scannell and Gifford (2010). Similarly, psychological distance was addressed by asking participants whether they had been personally affected by climate change. The responses of skeptical participants were organized according to the subthemes of saliency, legitimacy, and credibility proposed by Cash et al. (2002). An additional thread of analysis examined behavior change and the participants' willingness to mitigate and adapt to climate change.

\section{Results}

These results illuminate the central research question of the effectiveness of place-based communication for different facets of the American public. The representativeness of these results are assessed by comparing demographics with the U.S. Census data for California. Responses to the three test conditions shed light on the first research question of whether those exposed to a local framing of climate change would be more willing to mitigate and adapt to climate change. The second research question examines whether these results hold true for those with different values and beliefs, as categorized by the Six Americas. The final research question explores whether the theories of place attachment and psychological distance can help explain these results. The survey results are further explored qualitatively through follow-up interviews.

\section{a. Comparison of the survey population with the U.S. Census}

While the gender distribution of the sample population did not significantly differ from the California population as a whole, the sample is younger with lower household incomes and better education. The survey population has slightly more female respondents $(52 \%)$ than male $(48 \%)$, but this gender distribution is not significantly different from the most recent U.S. Census for California $\left[\chi^{2}(1, n=581)=0.96, p=0.32\right]$. The survey population is, however, significantly younger than the census population $\left[\chi^{2}(9, n=578)=356.49, p<\right.$ 0.001 ], with a mean age of 34.5 years and a greater percentage of survey respondents below the age of 40 (73\%) compared to the census $(40 \%)$.

Perhaps in part because of their younger age, the sample population also has lower average household incomes $\left[\chi^{2}(3, n=579)=79.58, p<0.001\right]$ than the California population. Twenty percent of both the surveyed and census populations have incomes under $\$ 25,000$, but only $15 \%$ of the survey population make over $\$ 100,000$ compared to $29 \%$ of Californians. Despite their lower incomes, the survey population is more educated $\left[\chi^{2}(3, n=583)=392.61, p<0.001\right]$ than average Californians, with $55 \%$ holding a bachelor's degree or higher compared to $24 \%$ in the census. All survey participants hold a high school diploma compared to $76 \%$ of the census population. 


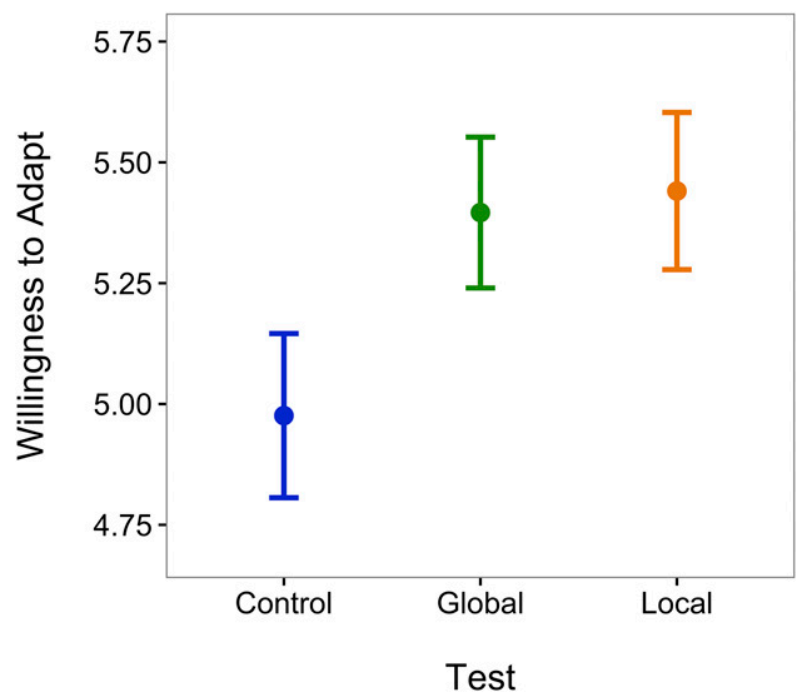

FIG. 2. Willingness to adapt is significantly different among the three test conditions (Kruskal-Wallis $\mathrm{H}$ test; $p<0.001$ ), with the control (blue) resulting in significantly less willingness to adapt than the global (green; $p=0.002$ ) or the local (orange; $p<0.001$ ). There is no significant difference between the local and global conditions ( $p$ $=1$ ). Willingness to adapt ranges from one (least willing) to seven (most willing). The circles represent the mean willingness to adapt. The bars represent the $95 \%$ confidence interval around the mean.

\section{b. The effect of test condition on participants' willingness to mitigate and adapt to climate change}

The test condition (local, global, or control) has an effect on willingness to adapt $[H(2)=18.03, p<0.001]$ but not on willingness to mitigate climate change $[H(2)=1.68, p=0.43]$. Due to this lack of significant response in willingness to mitigate, adaptation is focused on for the remainder of the analysis. Post hoc tests on willingness to adapt revealed that contrary to expectations, the global (mean rank $=313.90)$ and local (mean rank $=319.98$ ) are not significantly different $[H(2)=-6.08, p=1$ (Fig. 2)], but the response to the control condition (mean rank $=254.91$ ) is significantly less than both the global $[H(2)=-58.99, p=0.002]$ and the local $[H(2)=-65.07, p<0.001]$. These results suggest that for willingness to adapt, the effect of an intervention (reading an article connecting climate change to drought) was far more important than the framing of the intervention (local or global).

Willingness to adapt was divided into the subscales of personal adaptation and policy adaptation (Fig. 3) to examine the theory that proximal risk perceptions (and therefore a local framing) would be more effective at increasing support for personal adaptation measures, whereas the global framing would lead to support for broader policy measures (Brügger et al. 2015b). The difference between local and global framings is still not

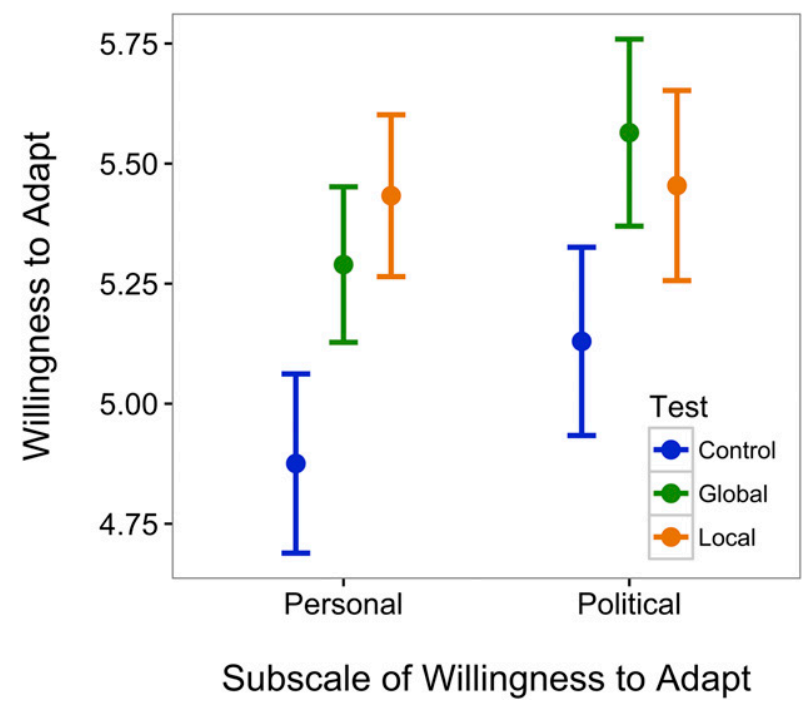

FIG. 3. Within the personal adaptation subscale (left), the local framing increased willingness to adapt the most, whereas within the policy subscale (right), the global framing was most effective. Willingness to adapt ranges from one (least willing) to seven (most willing). The circles represent the mean willingness to adapt within each of the subscales for the control (blue), global (green), and local (orange). The bars represent the $95 \%$ confidence interval around the mean.

significant: for the policy level $[H(2)=17.38, p=0.93]$; for the personal $[H(2)=-22.73, p=0.57]$. However, the policy subscale of willingness to adapt had the highest mean rank for the global (320.41) versus the local (303.03) or control (262.70). For the policy-level adaptation measures, the global and control are significantly different $[H(2)=-57.71, p=0.002]$, whereas the local and control are only nearly so $[H(2)=-40.33, p=$ 0.052]. In contrast, the personal subscale of willingness to adapt shows the highest mean rank for the local (327.59) as compared to the global (304.86) or control (256.50), and both the local and global are significantly different from the control $[H(2)=-71.09, p<0.001$ and $H(2)=-48.36, p=0.013$, respectively].

\section{c. The effect of prior values and beliefs on the response to the test condition}

The second research question focused on how different facets of the American public respond to climate change communication based on their prior beliefs and values about climate change, characterized according to the Six Americas (Maibach et al. 2011). There was an unequal division among the Six Americas, with the most participants in the concerned group (Fig. 4). The combined numbers of participants in the disengaged, doubtful, and dismissive groups make up less than a tenth of the total survey population, so the lack of significant results for these categories should be interpreted with caution. 


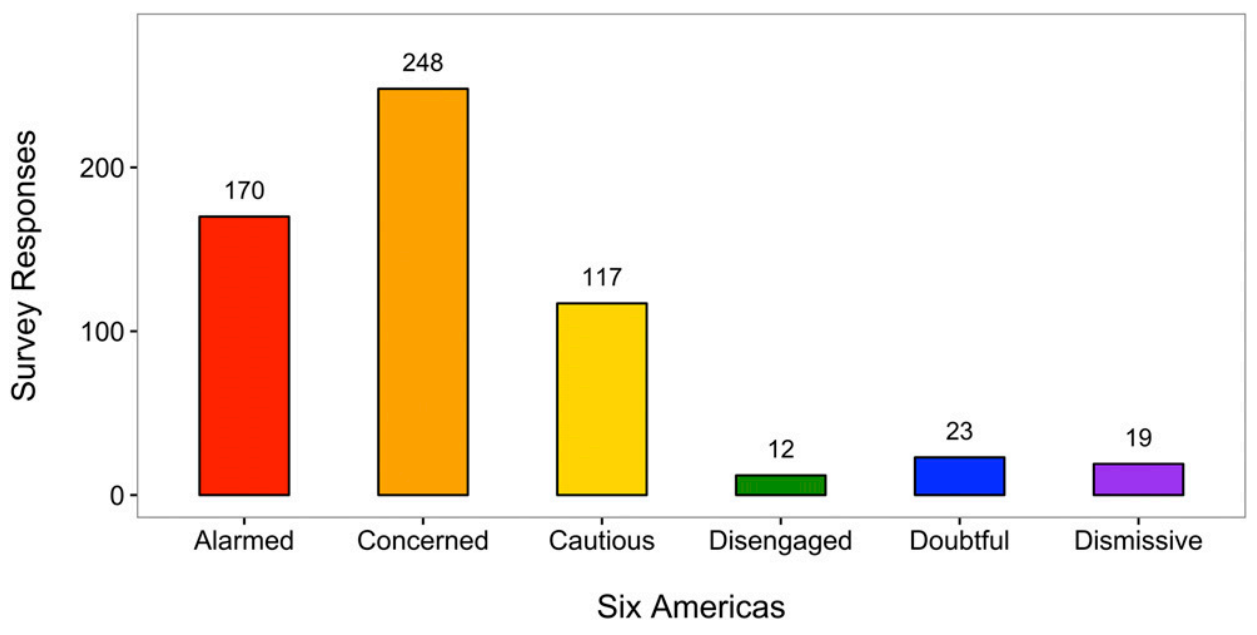

FIG. 4. The distribution of the 589 survey participants in each of the Six Americas. The concerned had the greatest proportion of participants $(42 \%)$, followed by the alarmed $(29 \%)$ and the cautious $(20 \%)$. The populations of the disengaged $(2 \%)$, doubtful $(4 \%)$, and dismissive $(3 \%)$ are relatively small.

Willingness to adapt varies highly among the Six Americas $[H(5)=241.45, p<0.001]$. The effect of the test condition is only significant within the largest group, the concerned $[H(2)=12.15, p=0.002]$, with $p>0.21$ for all other groups (Fig. 5). Post hoc tests for the concerned reveal that the control (mean rank $=102.79)$ was significantly different from the local [mean rank = 139.47, $H(2)=-36.68, p=0.003$ ] and the global [mean rank $=132.12, H(2)=-29.33, p=0.022]$, but the global and the local were not significantly different from one another $[H(2)=-7.35, p=1]$. This result indicates that prior beliefs and values influence the response to the test condition, as the effect of the intervention was only significant within one of the Six Americas (the concerned).

\section{d. The role of place attachment and psychological distance in mediating the response to place-based communication}

Place attachment explains a greater proportion of the variance in willingness to adapt among those who were exposed to either intervention compared to the control

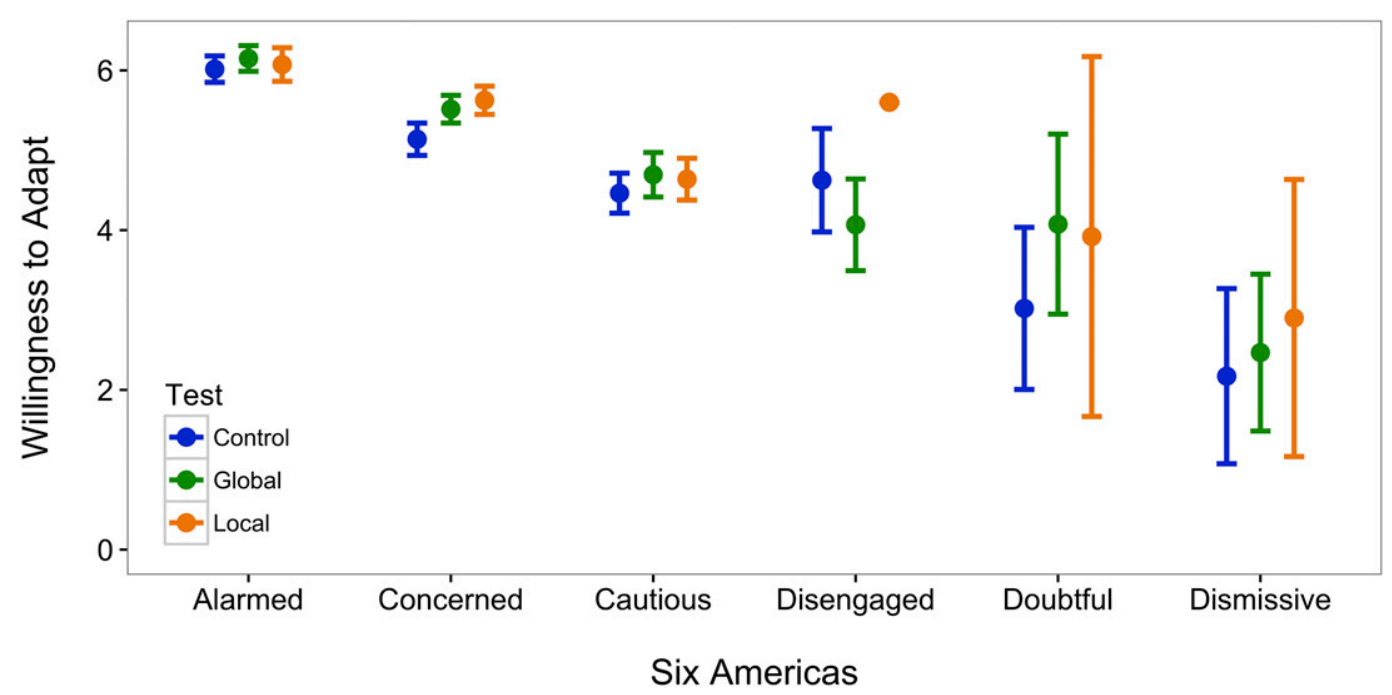

FIG. 5. The effects of test condition are only significant within the concerned (Kruskal-Wallis H test; $p=0.002$ ). Willingness to adapt ranges from one (least willing) to seven (most willing). The circles represent the mean willingness to adapt for the control (blue), global (green), and local (orange). The bars represent the $95 \%$ confidence interval around the mean. As there was only a single disengaged participant exposed to the local intervention, no error bar is depicted in this case. 
TABLE 1. Spearman's rho correlation of willingness to adapt with both place attachment and psychological distance in each of the test conditions. The coefficient indicates the strength of the correlation. A positive correlation with place attachment suggests that participants who feel more strongly attached to their geographic region are more willing to adapt to climate change. A negative correlation with psychological distance suggests that participants who believe that climate change is less psychologically distant are more willing to adapt to climate change.

\begin{tabular}{lcc}
\hline \hline Test & Place attachment & Psychological distance \\
\hline Control & $0.196^{* *}$ & $-0.619^{* *}$ \\
Global & $0.288^{* *}$ & $-0.559^{* *}$ \\
Local & $0.252^{* *}$ & $-0.399^{* *}$ \\
\hline
\end{tabular}

* Correlation is significant at the 0.05 level (2-tailed).

** Correlation is significant at the 0.01 level (2-tailed).

(Table 1). This suggests that attachment to place is one factor that mediates the participants' responses to a text about the role of climate change in the drought (whether local or globally framed), with those who had a higher attachment to place more willing to adapt to climate change than those who are less attached to California. In the control scenario, place attachment was still important in the participant's willingness to adapt to climate change but explained less of the variance.

As there is topographic, climatic, and demographic variation within the state, willingness to adapt to climate change was also examined at substate scales. There was no significant difference in willingness to adapt at the county scale $[H(42)=50.74, p=0.167]$, probably because of the small sample size in many of the counties (median number of responses $=5$ ). However, looking at the megaregions of northern and southern California with the boundary delineated by the northern limits of Kern, Bakersfield, and San Luis Obispo counties as in Benner and Pastor (2011), there was a significant difference in willingness to adapt between north (mean rank $=313.93$ ) and south [mean rank $=277.91 ; H(1)=$ $6.37, p=0.012$ ]. This may be partially explained by a higher attachment to place in northern California (mean rank $=313.83$ ) compared to southern California [mean rank $=277.98 ; H(1)=6.29, p=0.012]$.

Psychological distance, or how close people feel to climate change, explained more of the variance in willingness to adapt than place attachment (Table 1). However, unlike place attachment, the connection between psychological distance and willingness to adapt was weakest in the local condition. This indicates that for participants exposed to a local framing, perceived psychological distance of climate change plays less of a role in explaining their response to climate change communication.
TABLE 2. Spearman's rho correlation of willingness to adapt with both place attachment and psychological distance in each of the Six Americas. The coefficient indicates the strength of the correlation. A positive correlation with place attachment suggests that participants who feel more strongly attached to their geographic region are more willing to adapt to climate change. A negative correlation with psychological distance suggests that participants who believe that climate change is less psychologically distant are more willing to adapt to climate change.

\begin{tabular}{lcc}
\hline \hline Six Americas & Place attachment & Psychological distance \\
\hline Alarmed & $0.174^{*}$ & 0.019 \\
Concerned & $0.158^{*}$ & $-0.184^{* *}$ \\
Cautious & 0.137 & $-0.323^{* *}$ \\
Disengaged & $0.693^{*}$ & 0.039 \\
Doubtful & -0.203 & 0.099 \\
Dismissive & 0.144 & $-0.565^{*}$ \\
\hline
\end{tabular}

* Correlation is significant at the 0.05 level (2-tailed).

** Correlation is significant at the 0.01 level (2-tailed).

The Six Americas respond in different ways to place attachment and psychological distance (Table 2). For the alarmed and disengaged, place attachment is an important predictor of willingness to adapt, but psychological distance is not, whereas the opposite is true for the cautious and the dismissive (Table 2). Yet both place attachment and psychological distance are relevant for the concerned and neither for the doubtful (Table 2).

\section{e. Interview results}

Twelve interviews were conducted with two participants from each of the Six Americas. In the alarmed, concerned, cautious, and dismissive groups, one participant had been exposed to the local intervention and the other to the global. However, this was not possible in the case of the dismissive (one control, one local) and the disengaged (both controls, with the second participant noted with " 2 " in the following results) because of the low number of participants in those groups.

Interview participants were asked about extreme weather events that were happening elsewhere in the world, if this type of news affected their behavior, and how hearing news about events elsewhere compared to hearing about the California drought (see supplemental materials at the Journals Online website: https://doi.org/ 10.1175/WCAS-D-16-0119.s1 for interview questions). Nearly half of those interviewed did not care as much about events that were farther away or felt less able to do something about them. For instance, the doubtful, local participant remarked, "Hurricane Katrina ... can't occur where I live, so it doesn't affect me at all."

However, some of these same participants also said they worried more about events elsewhere in the world because of the greater vulnerability in developing countries. For instance, the concerned, global 
participant said, "I think it's more devastating to hear about it across the world than it is to hear about the drought ... [because] it probably affects them a lot more." Others felt that events elsewhere were similar to those in California because "it's one planet, one closed system" (dismissive, local). For another group, events elsewhere helped form part of a larger global picture of climate change.

In contrast to responses to events elsewhere in the world, interviewees seemed more concerned about events on a global scale. However, some still expressed a lack of selfefficacy: "What could I possibly do to help? ... What could I do to push the water back? To push the sea levels back?" (disengaged, control). Some felt a higher level of concern because of greater uncertainty about global events: "It's a little more worrisome 'cause, at least in the drought I can feel like I have a part in it and just kind of see it and gauge how things are going out here, but you never know what's going on in other underdeveloped parts" (disengaged, control 2). This response suggests that for this participant, global-scale events were farther away in the hypothetical dimension of psychological distance.

For others, the global scale provided a larger context for local experiences, such as the alarmed, global participant who remarked, "I knew it was happening pretty badly in California, I wasn't as aware that there were droughts going on all over the world, so I guess I would say that I felt troubled." Others saw manifestations of global events locally, such as the melting of ice sheets and sea level rise directly impacting the alarmed, local participant in that she "can't live as close to the beach because I know that in a couple years the water might rise higher." Contextualizing the local impacts of climate change within global trends suggests one reason for why the survey results indicated that the effectiveness of the global framing was highly correlated with place attachment to California.

When asked whether they like living in California and why to better understand place attachment, two-thirds of the participants specifically mentioned the climate. Some participants remarked on the past changes in climate or used the past tense, for example, "until recently I liked the climate" (concerned, local). Therefore, along with the effect of place attachment on climate change behaviors, there may be a feedback loop where a changing climate also influences place attachment.

The interview data substantiate the strong correlation between psychological distance and willingness to adapt to climate change across the Six Americas. For instance, the disengaged, control participant remarked, "I want to say [climate change] is not affecting me personally, but I want to say that because I don't know enough." On the other hand, both alarmed participants said that they felt climate change was affecting them personally, as did half of the participants from the concerned, cautious, and disengaged groups. When asked whether they felt personally affected by climate change to understand the social dimension of psychological distance, some referenced their humanity, for example, "It affects everyone. I'm human" (disengaged, control 2), whereas others were more specific, citing the effects of the drought. Another group of participants acknowledged that climate change may be affecting them personally but expressed greater concern for others.

While some participants identified personal impacts of climate change, others were more skeptical of anthropogenic climate change. These participants criticized the saliency, credibility, and legitimacy of the specific article used in the survey or the general discussion of climate change in the media. The doubtful, global participant questioned the legitimacy of the information by saying, "I just don't believe most of what they're saying. We've been lied to so much." Similarly the dismissive, local participant questioned the credibility of the data, remarking, "We're basically in the, the equivalent of standing in the middle of the wilderness with a broken compass and an inaccurate map. We don't really know what's going on. That's why global warming is definitely a hoax."

Saliency was also critiqued by a few participants, one of whom remarked on the larger concerns in the world, "Like here we have terrible, domestic and, you know, global political issues and President Obama says that the number one issue affecting us today is global warming" (dismissive, control). Another commented on personal saliency: "There are other things in my life ... I have to worry about more than some weather issues, as insensitive as that may sound" (disengaged, control). These responses illustrate why some groups might be dismissive of climate change, which influences how they react to place-based communication.

Questions about willingness to mitigate and adapt to climate change helped identify additional barriers, incentives, and motivations for behavior change. Results suggest that for nearly half of the interviewees, economic motivators were important. However, income was not significantly correlated with willingness to adapt among the survey participants as a whole $[H(5)=3.120$, $p=0.681]$. There were also varied responses about what, if anything, might influence the participants to change their behaviors around energy use (mitigation) or prepare for extreme weather events (adaptation). Some said they would be motivated by more information about what they could personally do or the situation becoming more drastic. Others said nothing would change their behavior, indicating different elasticity in willingness to change behaviors. 


\section{Discussion}

The primary goal of this research was to examine how and why different audiences respond to place-based climate change communication. Both willingness to mitigate and adapt were tested as measures of effectiveness, but there were no significant differences between the test conditions for willingness to mitigate. While mitigation and adaptation are correlated (Brügger et al. 2015b; Evans et al. 2014), the intervention (whether local or global) was only effective at shifting willingness to adapt (Fig. 2). This research also looks at for whom placebased communication is effective through the different results across the Six Americas, which characterizes participants based on their prior values and beliefs about climate change (Maibach et al. 2009). The response in willingness to adapt to place-based communication, particularly the key lack of difference between the local and the global framings, can be understood through applying the theories of place attachment and psychological distance.

\section{a. Responses to climate change communication for the entire sample population}

There are many potential explanations for the lack of difference between the local and the global framings of climate change communication. The premise that the local would be more effective was based upon its increased personal relevance (Lorenzoni and Hulme 2009; Lorenzoni and Pidgeon 2006; Schweizer et al. 2013). However, the interview results suggest that while the local is more relevant for some, the global is more relevant for others. If the local is not perceived as more relevant than the global, then this could provide a potential explanation for the lack of difference. Alternatively, the relatively higher concern about global events may be balanced by a perceived lack of self-efficacy (Spence and Pidgeon 2010).

In contrast to these results and those of Spence and Pidgeon (2010), other research has found significantly different responses between the local and global framings (e.g., Scannell and Gifford 2013). One of the major differences between this study and Scannell and Gifford's (2013) research is that the type of event they used to communicate local impacts (forest fires) was different from the phenomenon used to explain global impacts (polar ice caps melting). Whereas in this study, the local and global interventions were identical except for the place vocabulary. Because of the focus of both of these interventions on drought, it is possible that some participants (e.g., alarmed, global) felt that the global provided a larger context for what was already a local issue (Chapin and Knapp 2015). The different results between this study and Scannell and Gifford's (2013) research suggest that the type of extreme weather event can influence the response (Nerlich and Jaspal 2014).

In addition to what is communicated, there is also a question of how the effectiveness of the communication is measured. According to construal-level theory, which posits that the scale of perception and action will match (Trope and Liberman 2010), local framing may increase personal adaptation measures, whereas global framing may increase support for adaptation policy (Brügger et al. 2015b). This was supported by the data (Fig. 3), which indicate that the local and global framings might produce similar results in willingness to adapt but for different reasons. Therefore, communication efforts need to take into account whether support for adaptation on personal or policy fronts is desired.

The theory of psychological distance may also explain the similarity of the local and global framings through its correlation with willingness to adapt for the different test conditions (Table 1). A lower psychological distance, where climate change is perceived to be more proximate geographically, spatially, temporally, and hypothetically (Spence et al. 2012), is strongly correlated with a greater willingness to take action on climate change across all three test conditions (Table 1). However, psychological distance explains the least amount of variance in willingness to adapt among those exposed to the local condition. This suggests that views about the proximity of climate change may be transcended when faced with a local threat, such as when Florida residents who did not support climate change action on a national level wanted their local governments to address the impacts of climate change on sea level rise (Kahan 2014). However, this relationship between psychological distance and willingness to adapt is complex and warrants further study.

As Brügger et al. (2015a) discuss, place attachment is a precondition for the effectiveness of place-based communication, where decreasing psychological distance is only important if that is the scale at which people are attached to the place. The correlation between place attachment, or the emotional connections that people form with places (Lewicka 2011; Scannell and Gifford 2013, 2010), and willingness to adapt persists across all three test conditions (Table 1). While this correlation is weakest for the control condition, the strength of place attachment to California unexpectedly explains a slightly larger amount of variance for the global condition than the local (Table 1). One potential explanation is that place attachment to different scales is not independent but nested (Hess et al. 2008), so a global framing may trigger attachments to both the state and the planet. 
The results from this study do not provide support for the premise that a local framing of climate change is more effective than a global framing at increasing willingness to adapt. The similarity between the local and the global may occur for the following reasons:

1) changing psychological distance through local or global framing triggers different subscales of willingness to adapt (Brügger et al. 2015a),

2) place attachment occurs at multiple nested scales (Hess et al. 2008), or

3) the particular attributes of this sample population as different results may be found outside of California.

However, as both framings were more effective than the control (Fig. 2), the reported results do provide support for the use of climate change communication, and particularly event attribution statements, in changing willingness to adapt to climate change.

\section{b. The different responses to climate change communication among the Six Americas}

While both interventions were effective at increasing willingness to adapt to climate change, there is no general public (Thomas 2015), so the responses of groups with diverse beliefs and values may differ from the whole. Of the Six Americas, only the concerned group's willingness to adapt to climate change was affected by the intervention (Fig. 5).

One possible reason for this result is that reading an article has a small effect on behavior and is only detectable in the largest group, the concerned. As an effect of test condition persisted among the five other groups when the concerned were removed (Kruskal-Wallis $\mathrm{H}$ test, $p=0.018$ ), this finding warrants further research to see if the lack of effect persists in the other groups with larger samples. Nevertheless, there are other reasons why the concerned may be more likely to respond to climate change communication.

Seventy-nine percent of the concerned believe that global warming is "caused mostly by human activities" rather than "caused mostly by natural changes in the environment," "other," or "none of the above because global warming isn't happening" (Maibach et al. 2009). The belief in human-caused climate change, which leads to support for action (Spence et al. 2012; van der Linden et al. 2015), drops to less than half for the cautious $(49 \%)$, disengaged $(39 \%)$, doubtful $(8 \%)$, and dismissive (1\%) (Maibach et al. 2009). It follows that these groups might not respond as much to climate change communication, whether it is locally or globally framed.

While a greater percentage of the alarmed than the concerned believe in anthropogenic climate change (Maibach et al. 2009), the alarmed did not significantly respond to the intervention. This may be because the alarmed are the most informed about climate change (Maibach et al. 2009), limiting the effectiveness of additional information. Additionally, the alarmed may not be able to demonstrate increased action within the confines of the survey questions because they are not able to score any higher (Evans et al. 2014).

Another explanation for the response of the concerned comes from the relationships among willingness to adapt, place attachment, and psychological distance for each of the Six Americas (Table 2). The concerned were the only group where both place attachment and psychological distance were significantly correlated with willingness to adapt, suggesting that they may be uniquely situated to be responsive to place-based communication. While these results begin to suggest interactions between place attachment, psychological distance, and prior beliefs about climate change, this could be studied further.

The different responses among the Six Americas have implications for communication strategies. If it is indeed only the concerned who are significantly responding to the types of communication efforts used in this study, then future communication can be honed with the beliefs, values, and other characteristics of the concerned in mind. Other communication efforts can focus on the groups that did not respond to this particular style of intervention (e.g., van der Linden et al. 2015).

\section{Conclusions}

The three research questions addressed in this study were whether, for whom, and why place-based communication of climate change is effective at changing behaviors. Central findings are the similar response to locally and globally framed climate change communication and that both framings containing climate change attribution statements increased willingness to adapt. This suggests that global-scale communication may be as effective as the local when the type of extreme weather event is the same. Future studies could examine this finding further by comparing attribution statements for multiple types of events and at different scales.

Perhaps because drought was used for both local and global framings, place attachment did not help differentiate these responses. This supports the idea that place attachment at different scales may be nested (Hess et al. 2008). Furthermore, while this study focused on the effect of place attachment on willingness to adapt to climate change, there may be a feedback loop where a changing climate affects place attachment (Capstick et al. 2015; Hess et al. 2008). It may be important to consider place attachment as not a static or inherent 
quality but as a dynamic relationship that both influences responses to and can be influenced by climate change (Chapin and Knapp 2015).

There is a complex relationship between psychological distance and willingness to adapt to climate change. While these two variables were strongly correlated, decreasing psychological distance with a local framing led to more support for personal adaptation measures, and increasing psychological distance with a global framing led to more support for policy-level adaptation. This result supports Brügger et al.'s (2015a) contention that local framing of climate change is effective only under certain circumstances. Furthermore, the strength of the correlation with psychological distance was weakest among those exposed to the local framing, suggesting that under some circumstances, the desire to adapt to local extreme weather events may be more important to participants than their beliefs about the proximity of climate change.

This research supports the need for audience segmentation in climate change communication. Members of the Six Americas groups responded differently to place-based climate change communication in that only the concerned group showed a significant behavior change in response to the intervention. Additionally, the Six Americas were not equally influenced by place attachment and psychological distance. If these patterns hold in larger, more representative samples or in other places, then targeted communication strategies can be designed to increase effectiveness.

While the Six Americas are one way to understand an audience's beliefs and values, the general public is composed of many different groups (Thomas 2015). Research on the social basis for environmental concern examines how demographic factors such as age, political beliefs, gender, and education influence environmental and climate change beliefs (Liere and Dunlap 1980; Dietz et al. 1998; Hamilton et al. 2014). For instance, conservatives, particularly those that are also white and male (McCright and Dunlap 2011a), tend to be less concerned about climate change (McCright and Dunlap 2011b; Hamilton 2011; Dunlap et al. 2016). As a measure of climate change beliefs, the Six Americas study captures some demographic variables-for instance, the majority (58\%) of the alarmed group are Democrats and the majority $(64 \%)$ of the dismissive group are Republicans (Maibach et al. 2009). While some of these demographics may be captured in the Six Americas, it would be worthwhile to compare the results from future studies in other states or countries to this California case study to confirm the external validity of these results.

As there is no one California, other studies could build on these results about the differences in willingness to adapt to climate change at the regional scale by comparing responses to communication framed at state and substate scales and the corresponding place attachments at those scales. As drought severities differ across the state (National Drought Mitigation Center 2015) and some of the interview respondents indicated that economics were a barrier to action, perhaps the willingness to adapt to climate change could be considered in light of the participants' vulnerability and capacity to adapt to climate change. For instance, the low-income black communities who were more vulnerable during Hurricane Katrina (Yarnal 2007) may perceive climate change risks differently than those with greater privilege.

Another key area of research could use a stratified collection method within the Six Americas to overcome the unequal distribution of the population among the Six Americas, which is also seen in other studies (Maibach et al. 2009). The characteristics of the intervention provide another avenue for future research, as there are opportunities to explore different types of communication media (e.g., Shaw et al. 2009), different extreme weather events (e.g., Nerlich and Jaspal 2014), and alternative framings of climate change (e.g., Spence and Pidgeon 2010).

While there are many opportunities for further research, this study provides key insights into the placebased communication of climate change. These results suggest that a local experience of an extreme weather event may be leveraged for climate change adaptation, whether the extreme weather event is framed locally or the same type of event is communicated on a global scale. Making the link to climate change may be the key to translating the personal experience of extreme weather events into action (Newell et al. 2014). Action on climate change, by the many facets of the public, is central to meeting the challenge of adapting to and mitigating climate change.

Acknowledgments. We appreciate the excellent guidance and feedback from Graham Gottlieb at Climate Central, Amy Simon at Goodwin Simon Strategic Research, and three anonymous reviewers. We are also grateful to the 655 Californians who participated in this research. Financial support from the University of Oxford's Kellogg College and Environmental Change Institute is appreciated.

\section{REFERENCES}

AghaKouchak, A., L. Cheng, O. Mazdiyasni, and A. Farahmand, 2014: Global warming and changes in risk of concurrent climate extremes: Insights from the 2014 California drought. Geophys. Res. Lett., 41, 8847-8852, https://doi.org/10.1002/2014GL062308. 
Allen, M., 2003: Liability for climate change. Nature, 421, 891-892, https://doi.org/10.1038/421891a.

Beard, C. A., and J. L. Thompson, 2012: Engaging visitors in climate change communication: A case study of southern Florida's national parks and wildlife refuges. Appl. Environ. Educ. Commun., 11, 25-34, https://doi.org/10.1080/ 1533015X.2012.728062.

Benner, C., and M. Pastor, 2011: Moving on up? Regions, megaregions, and the changing geography of social equity organizing. Urban Aff. Rev., 47, 315-348, https://doi.org/10.1177/ 1078087410391950.

Billig, M., 2006: Is my home my castle? Place attachment, risk perception, and religious faith. Environ. Behav., 38, 248-265, https://doi.org/10.1177/0013916505277608.

Blasius, J., and V. Thiessen, 2012: Assessing the Quality of Survey Data. SAGE, 174 pp.

Brügger, A., S. Dessai, P. Devine-Wright, T. A. Morton, and N. F. Pidgeon, 2015a: Psychological responses to the proximity of climate change. Nat. Climate Change, 5, 1031-1037, https://doi. org/10.1038/nclimate2760.

_ , T. A. Morton, and S. Dessai, 2015b: Hand in hand: Public endorsement of climate change mitigation and adaptation. PLoS One, 10, e0124843, https://doi.org/10.1371/journal. pone. 0124843 .

Bryman, A., and D. Cramer, 2011: Quantitative Data Analysis with IBM SPSS 17, 18 and 19: A Guide for Social Scientists. Routledge, $377 \mathrm{pp}$.

Capstick, S. B., C. C. Demski, R. G. Sposato, N. F. Pidgeon, A. Spence, and A. Corner, 2015: Public perceptions of climate change in Britain following the winter 2013/2014 flooding. Cardiff University Understanding Risk Research Group Working Paper 15-01, $71 \mathrm{pp}$

Cash, D., W. Clark, F. Alcock, N. Dickson, N. Eckley, and J. Jäger, 2002: Salience, credibility, legitimacy and boundaries: Linking research, assessment and decision making. John F. Kennedy School of Government Working Paper RWP02-046, 25 pp.

Chapin, F. S., III, and C. N. Knapp, 2015: Sense of place: A process for identifying and negotiating potentially contested visions of sustainability. Environ. Sci. Policy, 53A, 38-46, https://doi.org/ 10.1016/j.envsci.2015.04.012.

Clifford, N., S. French, and G. Valentine, 2010: Key Methods in Geography. SAGE, 570 pp.

Climate Action Tracker, 2015: Climate pledges will bring $2.7^{\circ} \mathrm{C}$ of warming, potential for more action. Climate Action Tracker, accessed 1 October 2016, http://climateactiontracker.org/ news/253/Climate-pledges-will-bring-2.7C-of-warming-potentialfor-more-action.html.

Coleman, J. S. M., 2010: Spearman rank order correlation. Encyclopedia of Research Design, SAGE, 1404-1407, https://doi. org/10.4135/9781412961288.n428.

Creswell, J. W., and V. L. Plano Clark, 2011: Designing and Conducting Mixed Methods Research. 2nd ed. SAGE, 457 pp.

Devine-Wright, P., 2013: Think global, act local? The relevance of place attachments and place identities in a climate changed world. Global Environ. Change, 23, 61-69, https://doi.org/ 10.1016/j.gloenvcha.2012.08.003

Dietz, T., P. C. Stern, and G. A. Guagnano, 1998: Social structural and social psychological bases of environmental concern. Environ. Behav., 30, 450-471, https://doi.org/10.1177/ 001391659803000402.

Dunaway, F., 2015: Seeing Green. The Use and Abuse of American Environmental Images. University of Chicago Press, 344 pp.
Dunlap, R. E., A. M. McCright, and J. H. Yarosh, 2016: The political divide on climate change: Partisan polarization widens in the U.S. Environment, 58, 4-23, https://doi.org/10.1080/ 00139157.2016.1208995.

Evans, L., T. L. Milfont, and J. Lawrence, 2014: Considering local adaptation increases willingness to mitigate. Global Environ. Change, 25, 69-75, https://doi.org/10.1016/ j.gloenvcha.2013.12.013.

Funk, C., A. Hoell, and D. Stone, 2014: Examining the contribution of the observed global warming trend to the California droughts of 2012/13 and 2013/14 [in "Explaining Extreme Events of 2013 from a Climate Perspective"]. Bull. Amer. Meteor. Soc., 95 (9), S11-S15, https://doi.org/10.1175/1520-0477-95.9.S1.1.

Haden, V. R., M. T. Niles, M. Lubell, J. Perlman, and L. E. Jackson, 2012: Global and local concerns: What attitudes and beliefs motivate farmers to mitigate and adapt to climate change? PLoS One, 7, e52882, https://doi.org/10.1371/ journal.pone.0052882.

Hamilton, L. C., 2011: Education, politics and opinions about climate change evidence for interaction effects. Climatic Change, 104, 231-242, https://doi.org/10.1007/s10584-010-9957-8. J. Hartter, T. G. Safford, and F. R. Stevens, 2014: Rural environmental concern: Effects of position, partisanship, and place. Rural Sociol., 79, 257-281, https://doi.org/10.1111/ruso.12023.

Hart, P. S., and E. C. Nisbet, 2011: Boomerang effects in science communication: How motivated reasoning and identity cues amplify opinion polarization about climate mitigation policies. Commun. Res., 39, 701-723, https://doi.org/10.1177/ 0093650211416646

Hess, J. J., J. N. Malilay, and A. J. Parkinson, 2008: Climate change: The importance of place. Amer. J. Prev. Med., 35, 468-478, https://doi.org/10.1016/j.amepre.2008.08.024.

Holliday, A., 2007: Doing and Writing Qualitative Research. 2nd ed. SAGE, $199 \mathrm{pp}$.

Howe, P. D., M. Mildenberger, J. R. Marlon, and A. Leiserowitz, 2015: Geographic variation in opinions on climate change at state and local scales in the USA. Nat. Climate Change, $\mathbf{5}$, 596-603, https://doi.org/10.1038/nclimate2583.

Hulme, M., 2009: Why We Disagree about Climate Change: Understanding Controversy, Inaction and Opportunity. Cambridge University Press, 392 pp.

2014: Attributing weather extremes to "climate change": A review. Prog. Phys. Geogr., 38, 499-511, https://doi.org/ 10.1177/0309133314538644.

IPCC, 2014: Climate Change: Synthesis Report. Cambridge University Press, $151 \mathrm{pp}$.

Jorgensen, B. S., and R. C. Stedman, 2006: A comparative analysis of predictors of sense of place dimensions: Attachment to, dependence on, and identification with lakeshore properties. J. Environ. Manage., 79, 316-327, https://doi.org/10.1016/ j.jenvman.2005.08.003

Kahan, D. M., 2014: Climate-science communication and the measurement problem. Adv. Polit. Psychol., 36, 1-43, https:// doi.org/10.1111/pops.12244.

Kittur, A., E. H. Chi, and B. Suh, 2008: Crowdsourcing user studies with Mechanical Turk. Proc. 26th Annual Conf. on Human Factors in Computing Systems, Florence, Italy, Association for Computing Machinery, 453-456, https://doi.org/10.1145/ 1357054.1357127.

Krupa, J. S., D. M. Rizzo, M. J. Eppstein, D. B. Lanute, D. E. Gaalema, K. Lakkaraju, and C. E. Warrender, 2014: Analysis of a consumer survey on plug-in hybrid electric vehicles. Transp. Res., 64A, 14-31, https://doi.org/10.1016/j.tra.2014.02.019. 
Laczko, L. S., 2005: National and local attachments in a changing world system: Evidence from an international survey. Int. Rev. Sociol., 15, 517-528, https://doi.org/10.1080/03906700500272525.

Leiserowitz, A., 2007: Communicating the risks of global warming: American risk perceptions, affective images, and interpretive communities. Creating a Climate for Change: Communicating Climate Change and Facilitating Social Change, S. C. Moser and L. Dilling, Eds., Cambridge University Press, 44-63.

Lewicka, M., 2011: Place attachment: How far have we come in the last 40 years? J. Environ. Psychol., 31, 207-230, https://doi.org/ 10.1016/j.jenvp.2010.10.001.

Liere, K. D. V., and R. E. Dunlap, 1980: The social bases of environmental concern: A review of hypotheses, explanations and empirical evidence. Public Opin. Quart., 44, 181-197, https:// doi.org/10.1086/268583.

Lorenzoni, I., and N. F. Pidgeon, 2006: Public views on climate change: European and USA perspectives. Climatic Change, 77, 73-95, https://doi.org/10.1007/s10584-006-9072-z.

_, and M. Hulme, 2009: Believing is seeing: Laypeople's views of future socio-economic and climate change in England and in Italy. Public Understanding Sci., 18, 383-400, https://doi.org/ 10.1177/0963662508089540.

Maibach, E. W., C. Roser-Renouf, and A. Leiserowitz, 2009: Global warming's six Americas 2009: An audience segmentation analysis. Yale Project on Climate Change and George Mason University Center for Climate Change Communication Rep., 140 pp., http://climatecommunication.yale.edu/ publications/global-warmings-six-americas-2009/.

, A. Leiserowitz, C. Roser-Renouf, C. K. Mertz, and K. Akerlof, 2011: Global warming's six Americas screening tools. Yale Project on Climate Change Communication and George Mason University Center for Climate Change Communication Rep., 65 pp., http://climatecommunication.yale.edu/publications/globalwarmings-six-americas-screener-manual/.

McCright, A. M., and R. E. Dunlap, 2011a: Cool dudes: The denial of climate change among conservative white males in the United States. Global Environ. Change, 21, 1163-1172, https:// doi.org/10.1016/j.gloenvcha.2011.06.003.

— , and $-2011 \mathrm{~b}$ : The politicization of climate change and polarization in the American public's views of global warming, 2001-2010. Sociol. Quart., 52, 155-194, https://doi.org/10.1111/ j.1533-8525.2011.01198.x.

Nagourney, A., 2015: As California drought enters 4th year, conservation efforts and worries increase. New York Times, 17 March, A13, http://www.nytimes.com/2015/03/18/us/ascalifornia-drought-enters-4th-year-conservation-efforts-andworries-increase.html.

National Drought Mitigation Center, 2015: United States drought monitor. National Drought Mitigation Center, accessed 31 July 2015, http://droughtmonitor.unl.edu/.

Nerlich, B., and R. Jaspal, 2014: Images of extreme weather: Symbolising human responses to climate change. Sci. Cult., 23, 253-276, https://doi.org/10.1080/ 09505431.2013 .846311$.

Newell, B. R., R. I. McDonald, M. Brewer, and B. K. Hayes, 2014: The psychology of environmental decisions. Annu. Rev. Environ. Decis., 39, 443-467, https://doi.org/10.1146/ annurev-environ-010713-094623.

Nunnally, J. C., 1978: An overview of psychological measurement. Clinical Diagnosis of Mental Disorders, B. B. Wolman, Ed., Springer, 97-146, http://link.springer.com/chapter/10.1007/ 978-1-4684-2490-4_4.
O'Neill, S., and S. Nicholson-Cole, 2009: "Fear won't do it": Promoting positive engagement with climate change through visual and iconic representations. Sci. Commun., 30, 355-379, https://doi.org/10.1177/1075547008329201.

Otto, F. E. L., N. Massey, G. J. van Oldenborgh, R. G. Jones, and M. R. Allen, 2012: Reconciling two approaches to attribution of the 2010 Russian heat wave. Geophys. Res. Lett., 39, L04702, https://doi.org/10.1029/2011GL050422.

Pall, P., T. Aina, D. A. Stone, P. A. Stott, T. Nozawa, A. G. J. Hilberts, D. Lohmann, and M. R. Allen, 2011: Anthropogenic greenhouse gas contribution to flood risk in England and Wales in autumn 2000. Nature, 470, 382-385, https://doi.org/ 10.1038/nature09762.

Paolacci, G., and J. Chandler, 2014: Inside the Turk: Understanding Mechanical Turk as a participant pool. Curr. Dir. Psychol. Sci., 23, 184-188, https://doi.org/10.1177/ 0963721414531598.

Peer, E., J. Vosgerau, and A. Acquisti, 2014: Reputation as a sufficient condition for data quality on Amazon Mechanical Turk. Behav. Res. Methods, 46, 1023-1031, https://doi.org/ 10.3758/s13428-013-0434-y.

Scannell, L., and R. Gifford, 2010: Defining place attachment: A tripartite organizing framework. J. Environ. Psychol., 30, 1-10, https://doi.org/10.1016/j.jenvp.2009.09.006.

$\longrightarrow$, and — 2013: Personally relevant climate change: The role of place attachment and local versus global message framing in engagement. Environ. Behav., 45, 60-85, https://doi.org/10.1177/ 0013916511421196.

Schweizer, S., S. Davis, and J. L. Thompson, 2013: Changing the conversation about climate change: A theoretical framework for place-based climate change engagement. Environ. Commun., 7, 42-62, https://doi.org/10.1080/17524032.2012.753634.

Shaw, A., S. Sheppard, S. Burch, D. Flanders, A. Wiek, J. Carmichael, J. Robinson, and S. Cohen, 2009: Making local futures tangible-Synthesizing, downscaling, and visualizing climate change scenarios for participatory capacity building. Global Environ. Change, 19, 447-463, https://doi.org/10.1016/ j.gloenvcha.2009.04.002.

Simons, D. J., and C. F. Chabris, 2012: Common (mis)beliefs about memory: A replication and comparison of telephone and Mechanical Turk survey methods. PLoS One, 7, e51876, https://doi.org/10.1371/journal.pone.0051876.

Sippel, S., P. Walton, and F. E. L. Otto, 2015: Stakeholder perspectives on the attribution of extreme weather events: An explorative enquiry. Wea. Climate Soc., 7, 224-237, https://doi.org/10.1175/ WCAS-D-14-00045.1.

Smith, A., 2014: Older adults and technology use. Pew Research Center Rep., 27 pp., http://www.pewinternet.org/2014/04/03/ older-adults-and-technology-use/.

Spence, A., and N. Pidgeon, 2010: Framing and communicating climate change: The effects of distance and outcome frame manipulations. Global Environ. Change, 20, 656-667, https://doi.org/10.1016/j. gloenvcha.2010.07.002.

— W. Poortinga, and N. Pidgeon, 2012: The psychological distance of climate change. Risk Anal., 32, 957-972, https:// doi.org/10.1111/j.1539-6924.2011.01695.x.

Sprouse, J., 2011: A validation of Amazon Mechanical Turk for the collection of acceptability judgments in linguistic theory Behav. Res. Methods, 43, 155-167, https://doi.org/10.3758/ s13428-010-0039-7.

Stott, P. A., and P. Walton, 2013: Attribution of climate-related events: Understanding stakeholder needs. Weather, 68, 274-279, https:// doi.org/10.1002/wea.2141. 
D. A. Stone, and M. R. Allen, 2004: Human contribution to the European heatwave of 2003. Nature, 432, 610-614, https:// doi.org/10.1038/nature03089.

Swain, D. L., M. Tsiang, M. Haugen, D. Singh, A. Charland, B. Rajaratnam, and N. S. Diffenbaugh, 2014: The extraordinary California drought of 2013/2014: Character, context, and the role of climate change [in "Explaining Extreme Events of 2013 from a Climate Perspective"]. Bull. Amer. Meteor. Soc., 95 (9), S3-S7, https://doi.org/10.1175/15200477-95.9.S1.1.

Thomas, R. W. E., 2015: Informing conservation practice through environmental education: The "what", "how" and "why." The conservation social sciences: What?, How? and Why? Canadian Wildlife Federation and University of British Columbia Institute for Resources, Environment and Sustainability Rep., 40-43.

Trope, Y., and N. Liberman, 2010: Construal-level theory of psychological distance. Psychol. Rev., 117, 440-463, https:// doi.org/10.1037/a0018963.

UNFCCC, 2015: Paris Agreement. 21st Conference of the Parties to the United Nations Framework Convention on Climate Change, Paris, France, United Nations, 1-25, http:// unfccc.int/files/essential_background/convention/application/ pdf/english_paris_agreement.pdf.

University of Oxford, 2016: Research ethics (including CUREC). University of Oxford Research Support, accessed 16 October 2016, https://www.admin.ox.ac.uk/curec/.
U.S. Census Bureau, 2000: Educational attainment by sex: 2000, California. U.S. Census Bureau, accessed 28 July 2015, https:// factfinder.census.gov/bkmk/table/1.0/en/DEC/00_SF3/QTP20/ 0400000US06.

_, 2010: 2010 Census of population and housing, demographic profile summary file, California. U.S. Census Bureau, accessed 28 July 2015, https://factfinder.census.gov/bkmk/table/1.0/en/ DEC/10_DP/DPDP1/0400000US06.

van der Linden, S. L., A. A. Leiserowitz, G. D. Feinberg, and E. W. Maibach, 2015: The scientific consensus on climate change as a gateway belief: Experimental evidence. PLoS One, 10, e0118489, https://doi.org/10.1371/journal. pone.0118489.

Wilcox, R. R., 2004: Introduction to Robust Estimation and Hypothesis Testing. 2nd ed. Elsevier, 609 pp.

Williams, A. P., R. Seager, J. T. Abatzoglou, B. I. Cook, J. E. Smerdon, and E. R. Cook, 2015: Contribution of anthropogenic warming to California drought during 2012-2014. Geophys. Res. Lett., 42, 6819-6828, https://doi.org/10.1002/ 2015GL064924.

Willis, R., and N. Eyre, 2011: Demanding less: Why we need a new politics of energy. Green Alliance Rep., 40 pp., http://www. green-alliance.org.uk/resources/Demanding\%20less.pdf.

Yarnal, B., 2007: Vulnerability and all that jazz: Addressing vulnerability in New Orleans after Hurricane Katrina. Technol. Soc., 29, 249-255, https://doi.org/10.1016/ j.techsoc.2007.01.011. 